\title{
RESENHA CRÍTICA SOBRE O ARTIGO “OS PARADOXOS DA CONCILIAÇÃO”
}

Paula Paciullo de Oliveira

VIANA, Márcio Túlio. Os paradoxos da conciliação. Revista Ltr - legislação do trabalho, São Paulo, v. 78, n. 1,p. 7-16,jan. 2014.

O artigo "Os paradoxos da conciliação", de autoria de Márcio Túlio Viana, aborda como é a realidade da aplicação da solução de conflitos extrajudicial chamada conciliação na Justiça do Trabalho. Como o autor é professor e Juiz do Trabalho aposentado, compartilha de forma didática com o leitor sua experiência e a de colegas de trabalho na conciliação realizada no âmbito da Justiça do Trabalho. A obra foi escrita antes da Reforma Trabalhista (Lei 13.467/2017) ocorrida em 2017.

No decorrer da obra, o autor explicita os paradoxos, e, consequentemente, as desigualdades, que surgem em meio à conciliação na Justiça do Trabalho. Desde incoerências de natureza material, relacionadas ao direito do empregado - autor das ações na Justiça do Trabalho -, até incongruências de ordem processual. Como exemplo, cita-se a homologação da conciliação com o papel de sentença, sendo que a conciliação não é propriamente um instituto de direito processual, haja vista que é extrajudicial, logo caminha fora do processo.

O autor explica que, em uma relação processual trabalhista, o equilíbrio de poderes entre as partes no processo, que se apresentam aprioristicamente como iguais, com o mesmo peso e medida, não é assim na prática por causa de várias circunstâncias. A principal delas é porque o devedor - o empregador ou patrão - é quem tem o poder nessa relação processual, o poder de arcar ou não com a dívida quando bem entender e o credor - o empregado - que precisa desse valor em inadimplência para sobreviver, na maioria dos casos em que há uma lide trabalhista, fica refém da vontade de seu patrão ou ex-patrão. Muitas vezes, há magoas e ressentimentos entre as partes decorrentes da relação de trabalho existente, que se aproveitam do processo para externalizá-las. O autor conta que, em um dos processos em que analisou, o acordo estava pronto para ser aceito pelo empregador quando o empregado lhe disse que queria apenas ver o seu ex-patrão se sujeitar a um processo judicial e, logo após, sair da sala de audiência.

O autor continua; explicando que essa situação de precariedade do empregado frente ao empregador se agrava quando a Justiça é acionada apenas depois que a relação de emprego se encerrou. Desempregado e necessitando dos valores devidos para sustentar a si e a sua família, o empregado precisa urgentemente do pagamento dos valores devidos pelo empregador. A situação ainda se agrava porque o litígio demora em sua marcha. Sendo o tempo do processo diferente do tempo real, o trabalhador e sua família têm fome, carecem de moradia adequada, boas condições de sono e decente qualidade de vida. Com tal urgência e necessidade em receber alguma quantia, o empregado acaba aceitando acordos - isto é, conciliações - que não lhe são tão favoráveis. Em muitas celebrações desses acordos, os empregadores acabam pagando apenas parcialmente o 
valor do montante devido, ainda.

O autor também coloca que, aliada às circunstâncias acima descritas, os interesses pessoais de outras pessoas no processo contribuem para que a conciliação na Justiça do Trabalho não seja totalmente coerente e justa como deveria ser. O advogado do empregado, muitas vezes, depende da homologação do acordo para poder ganhar seus honorários e sobreviver deles o mais rápido possível. O juiz, abarrotado de processos de distintas complexidades, quer finalizar os processos menos complexos o mais rápido possível, para se delegar mais tempo e atenção aos complexos. A Justiça do Trabalho em si precisa recuperar seu prestígio e reputação, que hoje em dia estão desgastadas, perdendo suas forças e legitimidades. Comparando a Justiça do Trabalho com as demais - Federal e Comum -, vê-se como é ainda depreciada. Para o autor, o prestígio de cada Justiça está diretamente relacionado com o prestígio de seus destinatários, sendo o trabalhador o agente de menor importância na sociedade. Muitos têm, pois, a visão de que o Direito do Trabalho é uma subciência jurídica.

$\mathrm{O}$ autor também fala que o tempo pós-moderno, pragmático e flexível favorece a essa falta de proteção ao empregado ao passo que tudo é relativo, mais rápido e os direitos estão acompanhando essa tendência de flexibilização. O pequeno trabalhador teria, então, um pequeno direito, de importância menor e que deve ser resolvido rapidamente. Por outro lado, essa pós-modernidade pode trazer aspectos positivos, a depender do caso concreto. Na Justiça do Trabalho, depende da atuação do julgador: se tem boas intenções de realmente atender ao direito do trabalhador - ou de apenas julgar o processo o mais rápido possível para se concentrar em causas mais complexas, que, no pensamento dele, necessitem de mais atenção.

O autor mostra, ainda, que as regras do direito processual do trabalho atrapalham as regras do direito material. Traz como exemplo o artigo 846 da Consolidação das Leis Trabalhistas (CLT), que obriga o juiz a tentar conciliar, ou o artigo 625-A do mesmo diploma normativo, que regula as Comissões de Conciliação Prévia nas quais o juiz sequer está presente para dar uma chance ao empregado de ter um pouco de equilíbrio na relação.

Para o autor, a conciliação deveria ocorrer apenas nos casos da res dúbia: quando o processo é apenas consequência da dificuldade de delimitação sobre qual é o direito das duas partes. Na maioria das vezes, no entanto, a conciliação ocorre quando há a res litigiosa: quando o processo em si é o único elemento de incerteza, pois o direito está claro. Nesse caso, o direito é certo e não pode ser suprimido em benefício da outra parte. A que não tem o direito deve arcar com isto, então. O autor entende que a conciliação não foi criada para retirar direitos como, infelizmente, faz-se na prática.

Por fim, o autor entende que, para aparar essas desigualdades entre empregador e empregado no trabalho, deve-se evitar demandas, e, com isso, impossibilitar a própria existência do acordo de conciliação, melhorando a qualidade do emprego, constituindo uma real garantia de emprego mesmo que o empregado entre com processo contra o trabalhador. Na realidade, o empregado entra com um litígio contra o trabalhador porque perdeu seu emprego, ou é demitido porque entrou com a ação.

Com uma maior segurança fornecida pela garantia de emprego o patrão não violaria, em tese, tantos direitos do empregado, o que acarretaria em uma maior estabilidade. Aqui, o trabalhador não perderia seu 
sustento se buscasse seus direitos, eliminando um pouco a sua vulnerabilidade frente ao empregador. Demais soluções consistem em priorizar as ações coletivas, estendendo ao máximo o número de autores e demandando mais atenção do juiz, e enfatizar o fundo de indenizações trabalhistas, pois este permite ao empregado o acesso rápido ao valor que lhe foi reconhecido e concedido na sentença.

A majoração das taxas de juros de mora e o reconhecimento do poder-dever do juiz de aplicar multas e outras medidas também seriam boas alternativas para incentivas o empregador a pagar os débitos devidos ao trabalhador. Outra sugestão do autor é conceder a tutela provisória ao empregado para que ele possa, desde o início do processo, ter alguma fonte de sustento, não dependendo tanto da vontade do patrão de pagar ou não o devido.

Por fim, o autor conclui que a conciliação no âmbito da Justiça do Trabalho pode ser um bom instrumento se aplicado por um juiz mais sensível à situação social e financeira das partes, haja vista que tal acordo está cada vez mais parecido com a sentença e esta exige uma maior sensibilidade do julgador.

A conciliação, apesar de ser um instrumento muito útil e de fácil aplicabilidade, principalmente por ser uma alternativa interessante ao processo, o qual é longo, demorado, custoso e demanda muitos atos e formalidades, deve ser aplicada com parcimônia. Deve-se considerar que nem todos os direitos constituem-se como o Direito civil, em que as partes costumam ter maior paridade, igualdade nas relações, aderindo a um contrato por livre e espontânea vontade, acordando com cada cláusula ali escrita. No caso do Direito do Trabalho, as partes, desde o início da relação jurídica, são desiguais e as circunstâncias trazidas pela conciliação descritas pelo autor do texto mostram o empregado em uma maior situação de vulnerabilidade. Para culminar, há uma tendência de o juiz dar menos importância para seu direito individual, pois ele está preocupado em cumprir prazos e se debruçar mais atentamente em processos mais complexos.

Dessa forma, a conciliação deve ser utilizada com maior cuidado e atenção do julgador na Justiça do Trabalho, pois tais acordos não devem suprimir demasiadamente direitos ou atendê-los de forma muito tênue quando estão sendo drasticamente violados. E, se conciliação se constituir dessa maneira, há, praticamente, uma permissão e um incentivo às violações de direitos.

Antes de propor o acordo de conciliação, o juiz, por sua vez, pode usar de medidas típicas e atípicas para incentivar o adimplemento do empregador à satisfação do direito de seu empregado, aplicando multas com percentuais mais altos, penhora de bens, protesto e outras medidas correlatas, com fundamento no artigo 139, inciso IV do Código de Processo Civil (CPC/15), que pode ser aplicado no processo do trabalho conforme os requisitos do artigo 769 da Consolidação das Leis do Trabalho (CLT). Dentre as medidas sugeridas, a utilização de sistemas como o Infojud e o Renajud pode ser muito eficaz, pois, se aplicados quando o empregador se esquivar de sua obrigação, podem auxiliar o julgador em sua missão de satisfação do direito em lide, uma vez que tais instrumentos disponibilizam dados sobre o patrimônio das partes e constitui verdadeiro mecanismo de busca sobre os bens do devedor que podem ser penhorados para que haja adimplemento da dívida discutida em juízo. O objetivo maior do processo na Justiça do Trabalho é satisfazer o direito do empregado de forma célere e simplificada, de tal forma que esperar anos para que seu direito seja 
parcialmente satisfeito constitui-se como mais uma violação de direitos e acarretamento de inúmeros prejuízos.

Por fim, no contexto da Reforma Trabalhista, que entrou em vigor em 2017, a conciliação como mecanismo alternativo de resolução de conflitos está sendo utilizada com ainda mais frequência, seguindo a tendência lançada pelo CPC/15 e pelo movimento de flexibilização das leis e relações de direito processual trabalhista. Esta realidade aumenta a pertinência das críticas do autor e dos cuidados que o julgador deve tomar ao aplicar o instrumento dentro da relação processual, visto que o instrumento está sendo mais usualmente aplicado. Não é porque uma demanda é aparentemente mais simples do que outra que o juiz não deve se debruçar sobre ela e analisá-la com a devida cautela. 